\title{
Annual and semiannual variations in the ionospheric F2-layer: II. Physical discussion
}

\author{
H. Rishbeth ${ }^{1}$, I. C. F. Müller-Wodarg ${ }^{1,2}$, L. Zou ${ }^{1}$, T. J. Fuller-Rowell ${ }^{3}$, G. H. Millward ${ }^{2,3,4}$, \\ R. J. Moffett ${ }^{4}$, D. W. Idenden ${ }^{4}$, A. D. Aylward ${ }^{2}$ \\ ${ }^{1}$ Department of Physics and Astronomy, University of Southampton, Southampton S017 1BJ, UK \\ ${ }^{2}$ Atmospheric Physics Laboratory, University College London, 67-73 Riding House Street, London W1P 7PP, UK \\ ${ }^{3}$ CIRES, University of Colorado and NOAA Space Environment Center, 325 Broadway, Boulder, CO 80303, USA \\ ${ }^{4}$ School of Mathematics and Statistics, University of Sheffield, Sheffield S3 7RH, UK
}

Received: 21 April 1999 / Revised: 3 May 2000 / Accepted: 4 May 2000

\begin{abstract}
The companion paper by Zou et al. shows that the annual and semiannual variations in the peak F2-layer electron density $(N \mathrm{mF} 2)$ at midlatitudes can be reproduced by a coupled thermosphere-ionosphere computational model (CTIP), without recourse to external influences such as the solar wind, or waves and tides originating in the lower atmosphere. The present work discusses the physics in greater detail. It shows that noon $N \mathrm{mF} 2$ is closely related to the ambient atomic/molecular concentration ratio, and suggests that the variations of $N \mathrm{mF} 2$ with geographic and magnetic longitude are largely due to the geometry of the auroral ovals. It also concludes that electric fields play no important part in the dynamics of the midlatitude thermosphere. Our modelling leads to the following picture of the global three-dimensional thermospheric circulation which, as envisaged by Duncan, is the key to explaining the F2-layer variations. At solstice, the almost continuous solar input at high summer latitudes drives a prevailing summer-to-winter wind, with upwelling at low latitudes and throughout most of the summer hemisphere, and a zone of downwelling in the winter hemisphere, just equatorward of the auroral oval. These motions affect thermospheric composition more than do the alternating day/night (up-and-down) motions at equinox. As a result, the thermosphere as a whole is more molecular at solstice than at equinox. Taken in conjunction with the well-known relation of F2-layer electron density to the atomic/molecular ratio in the neutral air, this explains the F2-layer semiannual effect in $N \mathrm{mF} 2$ that prevails at low and middle latitudes. At higher midlatitudes, the seasonal behaviour depends on the geographic latitude of the winter downwelling zone, though the effect of the composition changes is modified by the large solar zenith angle at midwinter. The zenith angle effect is especially important in longitudes far from the magnetic poles. Here, the downwelling occurs at
\end{abstract}

Correspondence to: $\mathrm{H}$. Rishbeth

e-mail: hr@phys.soton.ac.uk high geographic latitudes, where the zenith angle effect becomes overwhelming and causes a midwinter depression of electron density, despite the enhanced atomic/ molecular ratio. This leads to a semiannual variation of $N \mathrm{mF} 2$. A different situation exists in winter at longitudes near the magnetic poles, where the downwelling occurs at relatively low geographic latitudes so that solar radiation is strong enough to produce large values of $N \mathrm{mF} 2$. This circulation-driven mechanism provides a reasonably complete explanation of the observed pattern of F2 layer annual and semiannual quiet-day variations.

Key words: Atmospheric composition and structure (thermosphere-composition and chemistry) Ionosphere (mid-latitude ionosphere; modelling and forecasting)

\section{The Modelling}

The preceding work by Zou et al. (2000), here called Paper I, gives details of the use of the coupled thermosphere-ionosphere-plasmasphere model CTIP (Fuller-Rowell et al., 1996; Millward et al., 1996b) to investigate the global morphology of the quiet F2-layer at midlatitudes. As explained in Paper I, the heat input due to auroral heat sources is taken from Fuller-Rowell and Evans (1987) and Evans et al. (1988), and the highlatitude electric convection field from Foster et al. (1986). The computations provide month-by-month global distributions of ionospheric and thermospheric parameters, at two levels of solar activity corresponding to $10.7 \mathrm{~cm}$ flux values of $F_{10.7}=100$ and $F_{10.7}=180$. All the computer runs include high-latitude particle precipitation and convection electric fields, appropriate to fairly quiet geomagnetic conditions $(K \mathrm{p}=2+$, $A \mathrm{p} \approx 9$ ). Most runs include middle/low-latitude electric fields as given by the model of Richmond et al. (1980), 
though some omit these electric fields. A few extra runs were made to investigate the effect of including or omitting tides. As in Paper I, we refer to "near-pole" and "far-from-pole" longitude sectors ("pole" here meaning magnetic pole), and denote zones of latitude as follows:

Equatorial: the zone within about $20^{\circ}$ of the magnetic equator, in which F2-layer behaviour is strongly influenced by the low-latitude system of electric fields;

Midlatitudes: zones between magnetic equatorial zone and auroral ovals, divided at roughly $45^{\circ}$ magnetic latitude into "lower" and "higher" midlatitudes (and of most concern to this work);

Auroral ovals: belts $10^{\circ}-15^{\circ}$ wide, the low latitude boundary being at about $75^{\circ}$ magnetic latitude at noon, and $66^{\circ}$ magnetic latitude at midnight;

Polar caps: regions poleward of the auroral ovals.

We also recall from paper I the anomalies observed at midlatitudes:

Winter or seasonal anomaly: $N \mathrm{mF} 2$ is greater in winter than in summer by day, but the anomaly disappears at night, $N \mathrm{mF} 2$ being greater in summer than in winter;

Semiannual anomaly: $N \mathrm{mF} 2$ is greater at equinox than at solstice;

Annual or non-seasonal anomaly: in the world as a whole, December $N \mathrm{mF} 2$ is on average greater than June $N \mathrm{mF} 2$, both by day and by night. An alternative description is that the seasonal anomaly is greater in the Northern than the Southern Hemisphere.

In the present work, Sect. 2 discusses the neutral O/ $\mathrm{N}_{2}$ concentration ratio as modelled by CTIP and how it is related to the electron density $N \mathrm{mF} 2$, and Sect. 3 deals with longitude variations of $N \mathrm{mF} 2$. Section 4 gives an overall description of the thermospheric circulation, and shows why the chemical composition varies semiannually at low and middle latitudes and thus causes the semiannual variation of F2-layer electron density, together with large winter maxima in "near-pole" longitude sectors at high middle latitudes. Section 5 returns to the question of the influences on the F2-layer of electric fields at low and middle latitudes. Section 6 discusses the possible mechanisms of the annual and semiannual variations in the F2-layer, and some other factors that may affect them; Sect. 7 is the conclusion.

\section{Relation of $\mathrm{NmF} 2$ to neutral air composition}

\subsection{Theory}

According to standard F2-layer theory (e.g. Rishbeth and Garriott, 1969), the midday F2-layer may be assumed to be in a nearly steady state. The height $h \mathrm{mF} 2$ of the F2-layer peak is determined by a balance between the electron loss (coefficient $\beta$ ) and plasma diffusion (coefficient $D$ ); it depends on the solar cycle, the solar zenith angle, and thermospheric winds. The peak electron density $N \mathrm{mF} 2$ is given approximately by the ratio $q / \beta$, where $\beta$ depends on the concentration of the molecular gases, $\mathrm{N}_{2}$ and to some extent $\mathrm{O}_{2}$. To sufficient accuracy for present purposes, the production rate $q$ may be written as

$q=I_{\infty} Q(Z, \chi) n[\mathrm{O}]$

where $n[\mathrm{O}]$ denotes the concentration of atomic oxygen, $I_{\infty}$ is the flux of ionizing solar radiation at the top of the atmosphere (integrated over the relevant part of the solar spectrum, and weighted with the appropriate efficiency factors for ionization of atomic oxygen), $Q(Z, \chi)$ is the well-known "Chapman function" of the solar zenith angle $\chi$, and $Z$ is reduced height (in units of the scale height $H$ ). As the height $h \mathrm{mF} 2$ tends to lie at a constant $Z$ (Paper I, Sect. 3.5), and is several scale heights above the peak of production, $Q(Z, \chi)$ varies little except when $\chi$ becomes large, over about $60^{\circ}$. At noon at midlatitudes, we can therefore take $Q(Z, \chi)$ as constant except in midwinter. The incident flux $I_{\infty}$ of course varies with solar cycle, and is taken to be proportional to $F_{10.7}$ (as discussed in Paper I). We may then write

$N \mathrm{mF} 2 \propto I_{\infty} Q(Z, \chi) n[\mathrm{O}] / n\left[\mathrm{~N}_{2}\right] \equiv I_{\infty} Q(Z, \chi) \mathscr{R}\left[\mathrm{O} / \mathrm{N}_{2}\right]$

which defines the symbol $\mathscr{R}\left[\mathrm{O} / \mathrm{N}_{2}\right]$ (we here ignore the contribution of molecular oxygen to the loss coefficient $\beta$, which should not matter too much because the distributions of $\mathrm{N}_{2}$ and $\mathrm{O}_{2}$ are similar in shape). Taking logarithms,

$\log N \mathrm{mF} 2=\log I_{\infty}+\log Q(Z, \chi)+\log \mathscr{R}\left[\mathrm{O} / \mathrm{N}_{2}\right]$

We now test whether $N \mathrm{mF} 2$ is closely related to the ratio $\mathscr{R}\left[\mathrm{O} / \mathrm{N}_{2}\right]$. If so, it follows that, for fixed solar conditions ( $I_{\infty}$ and $\chi$ constant), the quantity

$$
\begin{aligned}
\Delta & =\log N \mathrm{mF} 2-\left(\log n[\mathrm{O}]-\log n\left[\mathrm{~N}_{2}\right]\right) \\
& \equiv \log N \mathrm{mF} 2-\log \mathscr{R}\left[\mathrm{O} / \mathrm{N}_{2}\right]
\end{aligned}
$$

should be constant. But if, as suggested by Rishbeth (1986), we also take account of the way in which the plasma diffusion coefficient depends on the concentration [O], then a different combination of the $\mathrm{O}$ and $\mathrm{N}_{2}$ concentrations, which we call $\mathscr{R}^{\prime}\left[\mathrm{O} / \mathrm{N}_{2}\right]$, should fit $N \mathrm{mF} 2$ better. For this case we write

$$
\log N \mathrm{mF} 2=\log I_{\infty}+\log Q(Z, \chi)+\log \mathscr{R}^{\prime}\left[\mathrm{O} / \mathrm{N}_{2}\right]
$$

Again assuming fixed solar conditions, it follows that the quantity

$$
\Delta^{\prime}=\log N \mathrm{mF} 2-\left(1.3 \log n[\mathrm{O}]-0.7 \log n\left[\mathrm{~N}_{2}\right]\right) .
$$

should be constant, the numerical factors 1.3 and 0.7 being as given by Rishbeth (1986). In this case, the comparison between $N \mathrm{mF} 2$ and $\mathscr{R} '\left[\mathrm{O} / \mathrm{N}_{2}\right]$ is not heightsensitive, because $\mathscr{R}^{\prime}\left[\mathrm{O} / \mathrm{N}_{2}\right]$ is slowly varying with height, the reason being that the ratio of these factors, $1.3 / 0.7$, is nearly the same as the scale height ratio of $28 / 16$. Coincidentally, $\log \mathscr{R}^{\prime}\left[\mathrm{O} / \mathrm{N}_{2}\right]$ closely resembles the $P$-parameter discussed in Sect. 4.2. 
Table 1. Ranges of the differences $\Delta$ and $\Delta^{\prime}$

\begin{tabular}{llllllll}
\hline $\begin{array}{l}\text { Geographic } \\
\text { latitude }\end{array}$ & $56^{\circ} \mathrm{N}$ & $46^{\circ} \mathrm{N}$ & $36^{\circ} \mathrm{N}$ & $36^{\circ} \mathrm{S}$ & $46^{\circ} \mathrm{S}$ & $56^{\circ} \mathrm{S}$ & Combo \\
\hline $\begin{array}{c}\text { Range } \Delta \\
(\max -\min )\end{array}$ & 1.00 & 0.55 & 0.48 & 0.46 & 0.82 & 1.46 & 0.83 \\
$\begin{array}{c}\text { Range } \Delta^{\prime} \\
(\max -\min )\end{array}$ & 1.42 & 0.95 & 0.67 & 0.82 & 1.17 & 2.00 & 1.19 \\
\hline
\end{tabular}

\subsection{Maps of $\mathrm{O} / \mathrm{N}_{2}$ ratio and $\mathrm{NmF} 2$}

To test how closely the computed noon $N \mathrm{mF} 2$ is related to the $\mathrm{O} / \mathrm{N}_{2}$ ratio, we computed $N \mathrm{mF} 2$ as a function of month and longitude. For each of six latitudes, we test which of the ratios $\mathscr{R}\left[\mathrm{O} / \mathrm{N}_{2}\right]$ or $\mathscr{R}\left[\mathrm{O} / \mathrm{N}_{2}\right]$ gives a better fit to noon $N \mathrm{mF}$ 2, by computing the ranges of values of $\Delta$, namely $\Delta(\max -\min )$ and similarly for $\Delta^{\prime}$, namely $\Delta^{\prime}$ (max-min), as shown in Table 1 . The ranges are greatest for the two highest latitudes, $56^{\circ} \mathrm{N}$ and $\mathrm{S}$, partly because of the zenith angle effect in winter, and partly because of proximity to the auroral ovals in some longitude sectors. We also compute the ranges $\Delta$ and $\Delta^{\prime}$ of all the values of $\mathscr{R}$ and $\mathscr{R}^{\prime}$ at the four lower latitudes $\left(36^{\circ} \mathrm{N}\right.$ and $\mathrm{S}, 46^{\circ} \mathrm{N}$ and $\mathrm{S}$ ) taken together (denoted by "Combo" in Table 1). The values are expressed in natural logarithms, so a range of 1.0 in $\Delta$ (or $\Delta^{\prime}$ ) means that all the values on a given map of the ratio $\mathscr{R}$ (or $\mathscr{R}^{\prime}$ ) are consistent to within a factor of $\mathrm{e}=2.72$; a range of 0.5 means that they are consistent to within a factor of $\mathrm{e}^{0.5}=1.65$. The ranges of $\Delta$ are in every case less than those of $\Delta^{\prime}$, which implies that $N \mathrm{mF} 2$ is more closely related to the simple concentration ratio $\mathscr{R}\left[\mathrm{O} / \mathrm{N}_{2}\right]$ than to the ratio $\mathscr{R}^{\prime}\left[\mathrm{O} / \mathrm{N}_{2}\right]$. The seasonal changes of $N \mathrm{mF} 2$ agree only moderately well with those of $\mathrm{O} / \mathrm{N}_{2}$ ratio, partly because of the zenith angle effect, but also because of the seasonal variations of the poleward winds that depress $h \mathrm{mF} 2$ and $N \mathrm{mF} 2$, especially in winter.

\subsection{Complications}

Two matters complicate the relationships between $N \mathrm{mF} 2$ and the $\mathrm{O} / \mathrm{N}_{2}$ ratio. First, the F2-layer loss coefficient $\beta$, which is essentially determined by interchange reactions involving $\mathrm{O}^{+}$ions and neutral molecular gases, depends on both neutral $\mathrm{O}_{2}$ and $\mathrm{N}_{2}$. This should not much affect the form of the results, because the $\mathrm{O}_{2}$ and $\mathrm{N}_{2}$ concentrations are more or less proportional to one another. However, the reaction rates for both $\mathrm{O}_{2}$ and $\mathrm{N}_{2}$ may be affected by vibrational excitation (e.g. Pavlov, 1998), though not necessarily in the same way.

Second, the ambipolar or plasma diffusion coefficient $D_{\text {a }}$ (which helps to determine the height of the F2 peak), is inversely proportional to the ion-neutral collision frequency $v_{\text {in }}$, and this too depends on the concentrations of both $\mathrm{O}$ and $\mathrm{N}_{2}$. These complications are probably why Eq. (5), which assumes that $\beta$ depends only on the concentration of $\mathrm{N}_{2}$, and $v_{\text {in }}$ only on the concentration of $\mathrm{O}$, does not fit the model as well as Eq. (3).

\section{Longitude variations of CTIP parameters at fixed latitudes}

As mentioned in Sect. 3.1 of Paper I, longitude variations are found in the maps of electron density, noon $N \mathrm{mF} 2$ being greater in some eastern longitudes than in western. According to the theory outlined in Sect. 2, $\mathrm{NmF} 2$ is determined by composition and height, and as the height is strongly influenced by the meridional wind, there is a complex interaction between the different physical factors. To investigate this, we made contour maps of four CTIP parameters versus magnetic longitude and month, namely $N \mathrm{mF} 2, h \mathrm{mF} 2$, and the $\left[\mathrm{O} / \mathrm{N}_{2}\right]$ ratio and southward neutral air wind velocity $U_{\mathrm{s}}$ calculated at the height $h \mathrm{mF} 2$. We made plots for six magnetic latitudes, $36^{\circ}, 46^{\circ}, 56^{\circ}$ North and South, as we found that the CTIP parameters are better ordered by magnetic than by geographic latitude. Figure 1 gives two examples. Zero longitude is reckoned eastwards from the $78^{\circ} \mathrm{W}$ geographic meridian which passes through the north magnetic (dip) pole.

The amount of structure in the maps (even in magnetic coordinates) shows that the interaction of the four parameters is indeed complicated. There is some relationship, but not a close one, between $U_{\mathrm{s}}$ and $h \mathrm{mF} 2$, which has some effect on $N \mathrm{mF} 2$. We find that the maps of $N \mathrm{mF} 2$ and $\mathrm{O} / \mathrm{N}_{2}$ ratio have some similarity, in accordance with the relationships described in Sect. 2.2. In particular, in the Eurasian sector at magnetic longitudes $120^{\circ}-180^{\circ}$, the January-February and October-November peaks in the two parameters roughly coincide, though in northern summer (June in the lefthand plots for $46^{\circ} \mathrm{N}$ magnetic latitude) there is little variation with longitude.

In winter at higher midlatitudes the situation is strikingly different, as clearly shown in the right-hand plots $\left(56^{\circ} \mathrm{S}\right.$ magnetic). The June (midwinter) region of high electron density is centred at about $-90^{\circ}$ magnetic longitude, in the Australasian sector, in a region of moderately high $\mathrm{O} / \mathrm{N}_{2}$ ratio. Further east, however, centred near magnetic longitude $0^{\circ}$ in the South Atlantic/Antarctic sector, maximum $\mathrm{O} / \mathrm{N}_{2}$ ratio coincides with a very deep minimum of $N \mathrm{mF} 2$. As discussed by Rishbeth and Müller-Wodarg (1999), the reason is that the region of strong downwelling, which greatly enhances the $\mathrm{O} / \mathrm{N}_{2}$ ratio, lies at high geographic latitude which is in midwinter darkness. In terms of Eq. (3), the function $Q(Z, \chi)$ is so small, indeed almost zero, that $N \mathrm{mF} 2$ is small despite the very large $\mathrm{O} / \mathrm{N}_{2}$ ratio. A similar effect is seen in the corresponding "far-frompole" (East Asian) sector in high northern midlatitudes but, because of the smaller difference between magnetic and geographic latitudes in the north, the effect is not as strong as in the south.

The only physical factor in CTIP that can produce longitude-dependent features is the magnetic field configuration. Figure 2 plots against longitude the 
CTIP Model

$F 10.7=100$

$\mathrm{Kp}=2+$

noon

$46 N_{\text {mag }}$
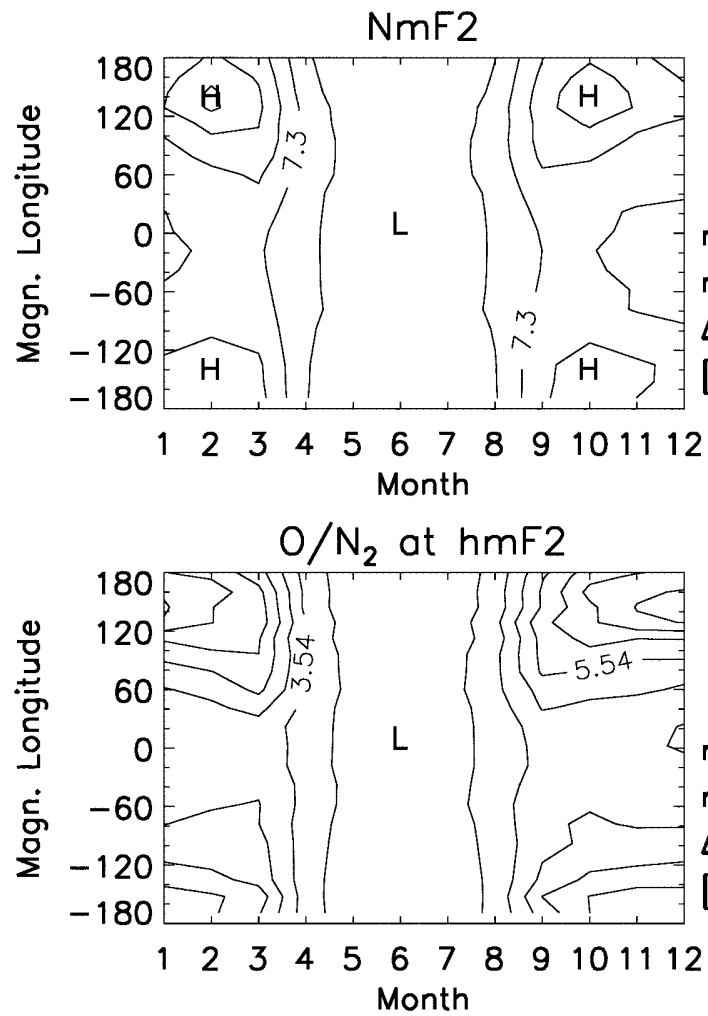

hmF2

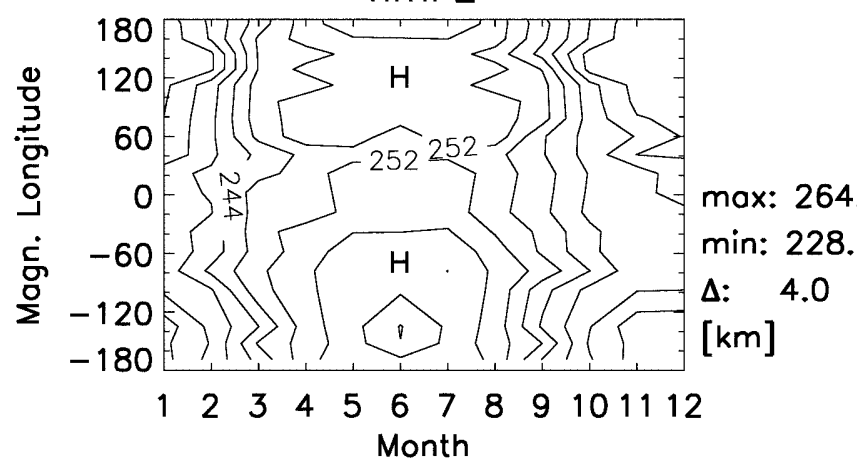

Southward Wind

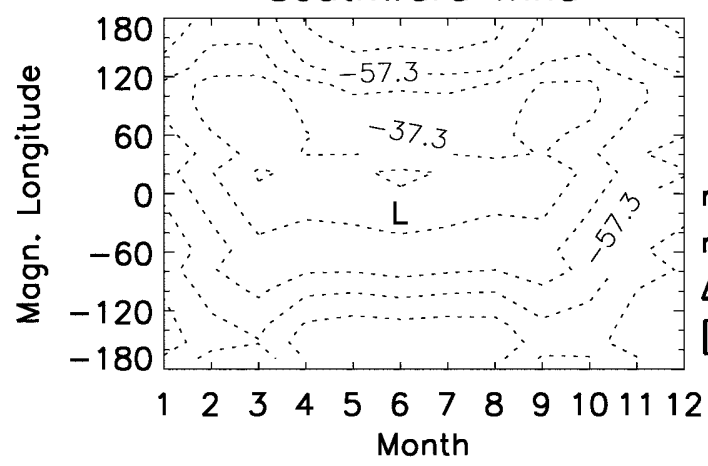

max: -25.7 $\min :-77.3$ $\Delta: \quad 10.0$ $[\mathrm{m} / \mathrm{s}]$

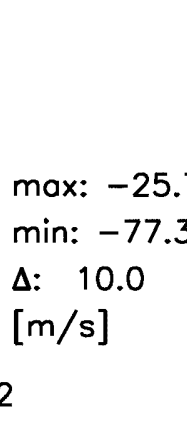

\section{$56 S_{\text {mag }}$}
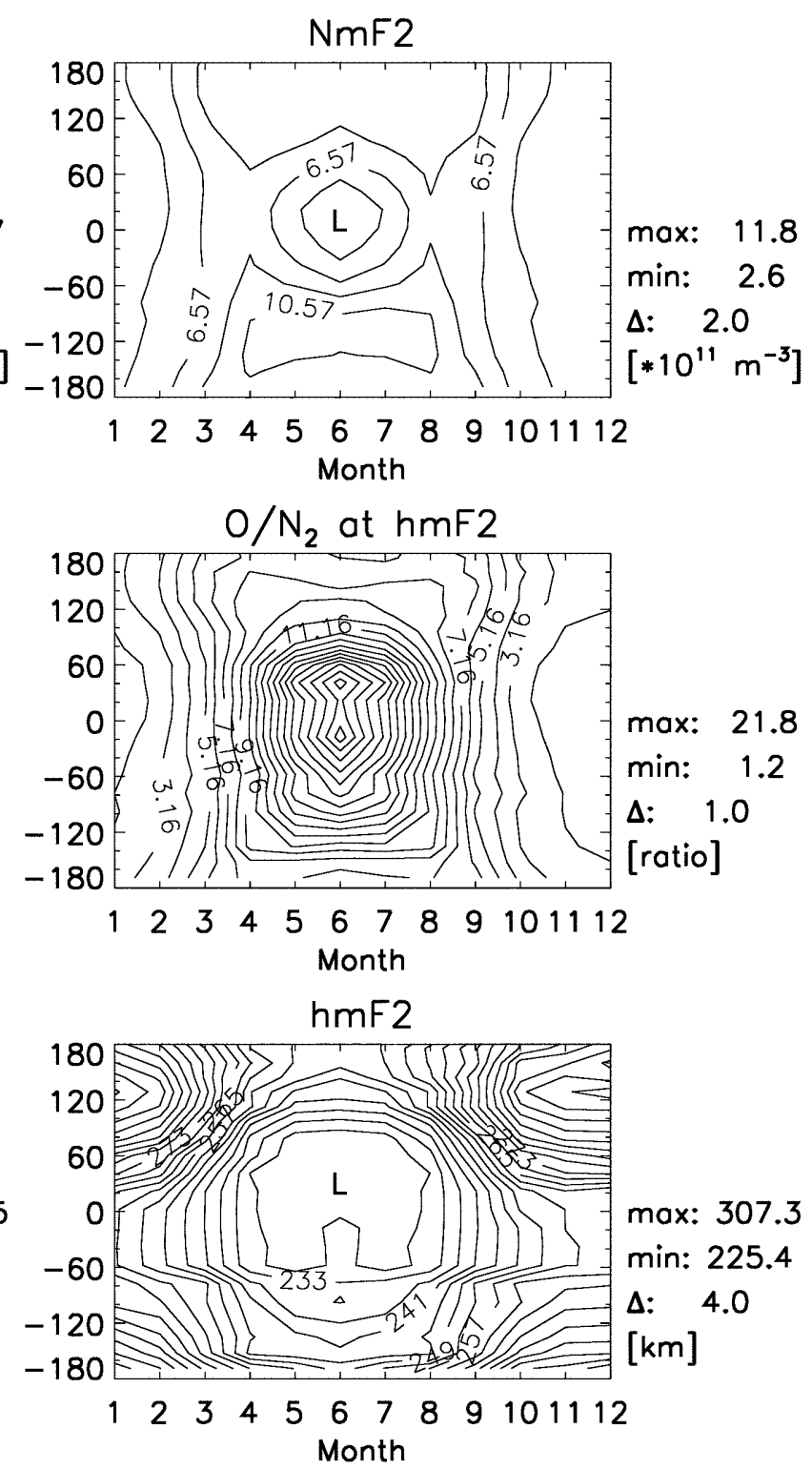

Southward Wind

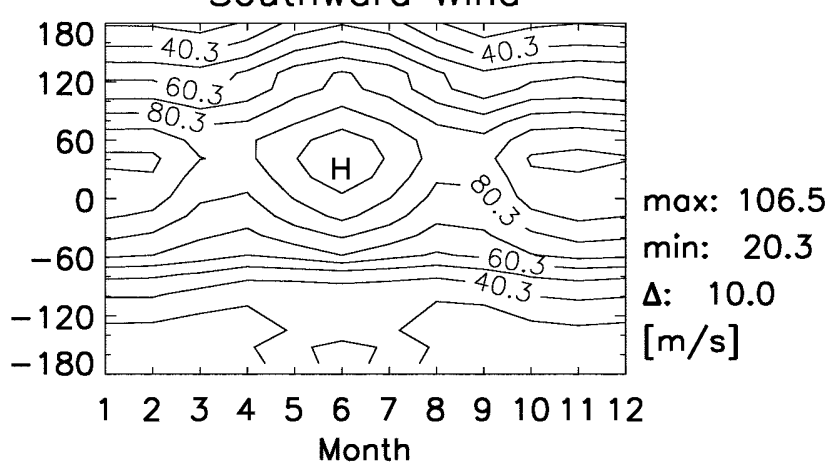


Fig. 1. Contour maps of (top to bottom) $N \mathrm{mF} 2$, ratios $\mathscr{R}\left[\mathrm{O} / \mathrm{N}_{2}\right]$ at $\mathrm{F} 2$ peak, $h \mathrm{mF} 2$ and southward wind versus month at magnetic latitudes $46^{\circ} \mathrm{N}$ (left) and $56^{\circ} \mathrm{S}$ (right). ' $H$ ' denotes 'high', ' $L$ ' denotes 'low'. Maximum and minimum values and contour intervals are shown

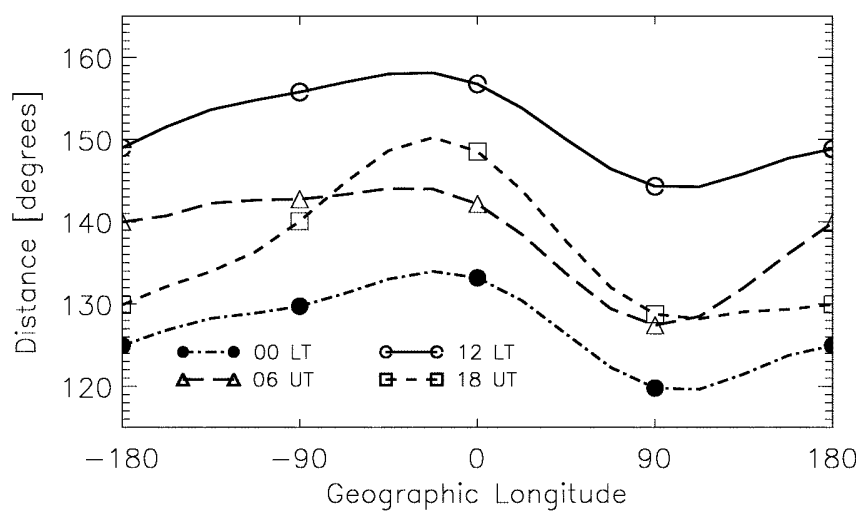

Fig. 2. Latitudinal distance between the north and south ovals, i.e., the arithmetic sum of the geographic latitudes of the north and south ovals, at $00 \mathrm{LT}$ (dash-dot curves), $06 \mathrm{LT}$ (long dashes), $12 \mathrm{LT}$ (solid curves), and 18 UT (short dashes)

separation (in degrees of latitude) between the north and south ovals, i.e., the arithmetic sum of the latitudes shown in Fig. 4 of Paper I. The curves are drawn for four local times. Near $90^{\circ} \mathrm{W}$, the separations range between about $130^{\circ}$ and $160^{\circ}$, as compared to about $120^{\circ}$ to $145^{\circ}$ near $90^{\circ} \mathrm{E}$, so the north and south ovals are further apart in the western hemisphere than in the eastern. If the separations are measured between the centres of the auroral ovals, instead of their equatorward edges, they are $10^{\circ}-15^{\circ}$ greater but the general pattern is much the same.

\section{An overall description of the thermospheric circulation}

\subsection{Wind patterns and their effects}

We now examine in more detail how the composition varies with latitude throughout the year, as a step towards developing an overall description of the quietday thermospheric circulation. The idea that a global circulation causes the seasonal changes of composition was put forward by Johnson (1964) and King (1964). King attributed the composition change to the progressive dissociation of $\mathrm{O}_{2}$ molecules as the air travels from the summer to the winter hemisphere, thus increasing the atomic/molecular ratio (it being thought at the time that $\mathrm{O}_{2}$ plays a major part in the loss of ionization). The role of the circulation in producing both the seasonal and storm effects in the F2-layer was further discussed by Duncan (1969).

Our modelling supports the following picture, essentially that envisaged by Duncan (1969). Upwelling in the summer hemisphere and in the tropics causes upward transport of gases rich in molecular nitrogen. This leads to an overall decrease of the $\mathrm{O} / \mathrm{N}_{2}$ ratio on given pressure-levels. The reverse, a downwelling and increase of the $\mathrm{O} / \mathrm{N}_{2}$ ratio, occurs in winter months. This behaviour is modified at high latitudes, where auroral heating causes upwelling during winter months too, thus reducing the $\mathrm{O} / \mathrm{N}_{2}$ ratio in winter as well as in summer (Millward et al., 1996a). At low-to-middle latitudes, the $\mathrm{O} / \mathrm{N}_{2}$ ratio has a clear semiannual variation at some longitudes (Fig. 1). Fuller-Rowell (1998) has proposed a mechanism that he calls the "thermospheric spoon". Essentially, he argues that at equinox the weaker meridional winds cause less mixing (or "stirring", to use the "spoon" analogy), thus enabling gases to attain a state closer to diffusive equilibrium, as compared with solstice. As further discussed in Sect. 4.2, a key role is played by the meridional winds. At solstice, there is an overall circulation from the summer to the winter hemisphere, with daily averaged (prevailing) meridional winds of about $25 \mathrm{~m} \mathrm{~s}^{-1}$ in middle and low latitudes (Fig. 3). These winds carry the nitrogen-rich air produced by upwelling at higher latitudes in the summer hemisphere into lower latitudes, thus reducing the $\mathrm{O} / \mathrm{N}_{2}$ ratio. So at equinox, when there is no prevailing meridional circulation, the $\mathrm{O} / \mathrm{N}_{2}$ ratio at low latitudes is larger than at either solstice, which results in a semiannual variation. Although molecular diffusion tends to smooth out the composition differences, making them smaller than they would otherwise be, we shall see that it by no means destroys them.

\subsection{Zonal averages of the composition P-parameter}

The thermospheric composition parameter

$P=28 \ln [\mathrm{O}]-16 \ln \left[\mathrm{N}_{2}\right]+12 \ln \mathrm{T}$

was introduced by Rishbeth et al. (1987) for their investigation of composition changes during F-region storms, and was used by Rishbeth and Müller-Wodarg (1999) to investigate seasonal composition changes in the quiet-day thermosphere. This parameter, which is closely related to the $\mathrm{O} / \mathrm{N}_{2}$ ratio, is independent of height in a static thermosphere that is in "hydrostatic" or "gravitational" equilibrium. Though the air as a whole is almost exactly in gravitational equilibrium, vertical motions in the thermosphere cause the individual distributions of $\mathrm{O}$ and $\mathrm{N}_{2}$ to depart slightly from that situation, in which case $P$ varies with height.

Calculations with CTIP show that $P$ and its global average $\langle P\rangle$ are systematically different at equinox and solstice, and so are the prevailing southward winds $\left(U_{\mathrm{s}}\right)$ crossing the geographic equator (the horizontal winds do not vary much with latitude between $50^{\circ} \mathrm{N}$ and $50^{\circ} \mathrm{S}$ ). At pressure-level $Z=12$, near the daytime F2-peak, and for $F_{10.7}=100$, the zonally averaged equatorial values of $P$ and the global averages $\langle P\rangle$ are:

December: $P=515, U_{\mathrm{s}}=-29 \mathrm{~m} \mathrm{~s}^{-1},\langle P\rangle=517.9$

March: $P=520, U_{\mathrm{s}}=-1 \mathrm{~m} \mathrm{~s}^{-1},\langle P\rangle=525.2$

June: $P=515, U_{\mathrm{s}}=+27 \mathrm{~m} \mathrm{~s}^{-1},\langle P\rangle=517.8$

Absolute values of $P$ are not important. The importance lies in the equinox-to-solstice differences of 5 units at the 

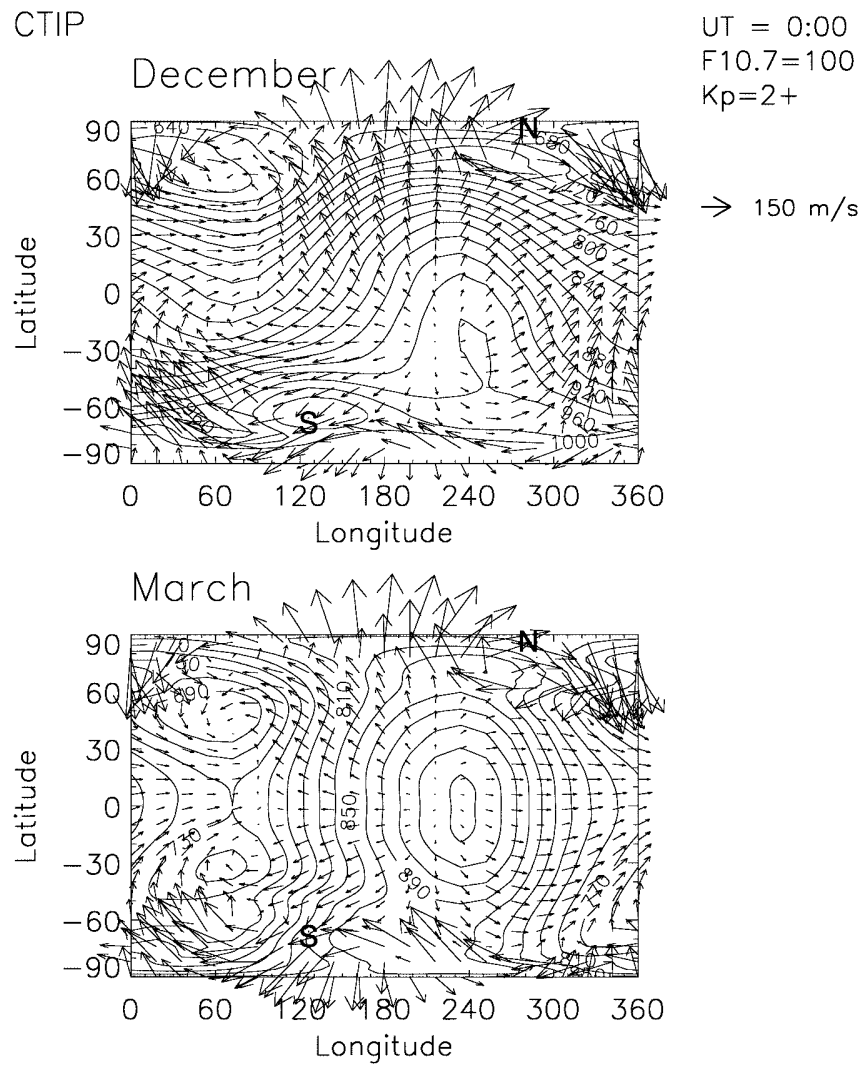

$$
\begin{aligned}
& F 10.7=100 \\
& K p=2+
\end{aligned}
$$

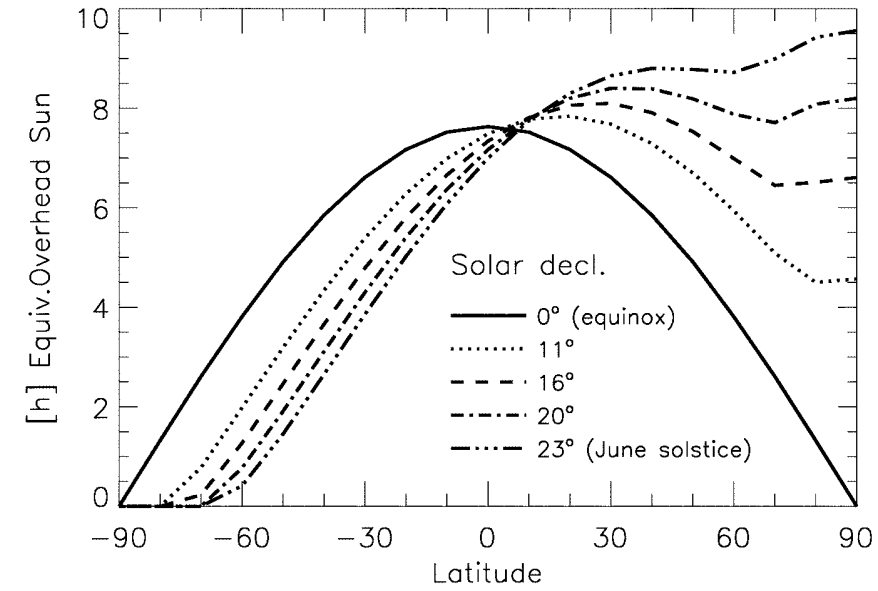

Fig. 4. Total solar irradiation $J$, expressed as the number of hours of equivalent overhead sun, versus latitude for several solar declinations: $0^{\circ}$, equinox $(-) ; 11^{\circ}, 1$ month from equinox (....); $16^{\circ}, 11 \frac{1}{2}$ months from equinox (- - -); $20^{\circ}, 1$ month from June solstice $(-\cdot-\cdot-) ; 23^{\circ}$, June solstice $(-\cdots-)$. The curves apply to the opposite seasons if the latitude scale is reversed

$J=\int \cos \chi \mathrm{d} t$

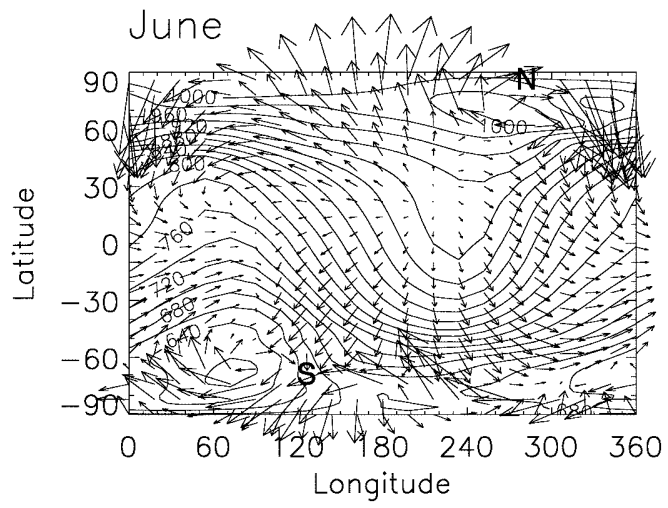

where $\chi$ is solar zenith angle. To understand Fig. 4, it may be helpful to consider two special cases. First, the equator at equinox: $\chi$ varies at a constant rate from $0^{\circ}$ at noon to $180^{\circ}$ at midnight, so the integral from sunrise to sunset gives $J=24 / \pi=7.6 \mathrm{~h}$. Second, the pole at summer solstice: $\chi$ is constant at $66.5^{\circ}$, and $\cos 66.5^{\circ}=0.4$, so $J=24 \times 0.4=9.6 \mathrm{~h}$. To show that conditions do not change much for almost three months around each solstice, Fig. 4 shows curves for five solar declinations: $0^{\circ}$ for equinox, $11^{\circ}$ for 1 month from equinox, $16^{\circ}$ for 1.5 months from equinox, $20^{\circ}$ for 2 months from equinox, and $23.5^{\circ}$ for solstice. As the annual variation of Sun-Earth distance is neglected, the plots of $J$ versus latitude may be reversed to represent southern summer.

Figure 4 shows that $J$ at midsummer exceeds $8 \mathrm{~h}$ at $Z=15$, plotted in latitude and longitude, for 00 UT in December, March and June. The noon meridian, $180^{\circ}$, is in the centre. Letters $N$, $S$ mark the positions of the magnetic poles

equator, which represent differences of $25-30 \%$ in the $\mathrm{O} / \mathrm{N}_{2}$ ratio, and in the global averages $\langle P\rangle$ of about 7 units.

What causes the equinox-solstice difference? The thermospheric circulation is driven by solar EUV radiation, with a contribution at high latitudes from sources of magnetospheric origin, namely particle precipitation and convection electric fields. Mixing is greatest at summer solstice because the heat input is extensive in area and sustained in time, whereas at equinox no part of the Earth is in continuous sunlight. Averaged over 24 hours, the EUV heating effect is almost uniform with latitude in most of the summer hemisphere. Figure 4 shows plots versus latitude, for five different times of year, of the "total daily insolation" all latitudes from $15^{\circ}$ to the pole. Averaging over the entire hemisphere, the total insolation is equivalent to $8.4 \mathrm{~h}$ of vertical sunlight at summer solstice, as compared to $3.6 \mathrm{~h}$ at winter solstice and $6 \mathrm{~h}$ at equinox. Reinforcing this seasonal imbalance, the heating due to auroral sources is also greatest in summer, because of the greater E-region electron density and conductivity (it being assumed in the model that the particle precipitation and electric fields do not vary with season).

\subsection{The meridional circulation at solstice}

The heat input drives upwelling at high and middle latitudes in the summer hemisphere. Figure 5 shows that this upwelling disturbs the vertical distribution of $\mathrm{O}$ and 


$$
\begin{array}{cc}
\text { CTIP Model } & \mathrm{F} 10.7= \\
& \mathrm{K} \text {-Parameter } \\
\text { zonal average } &
\end{array}
$$$$
\text { December }
$$
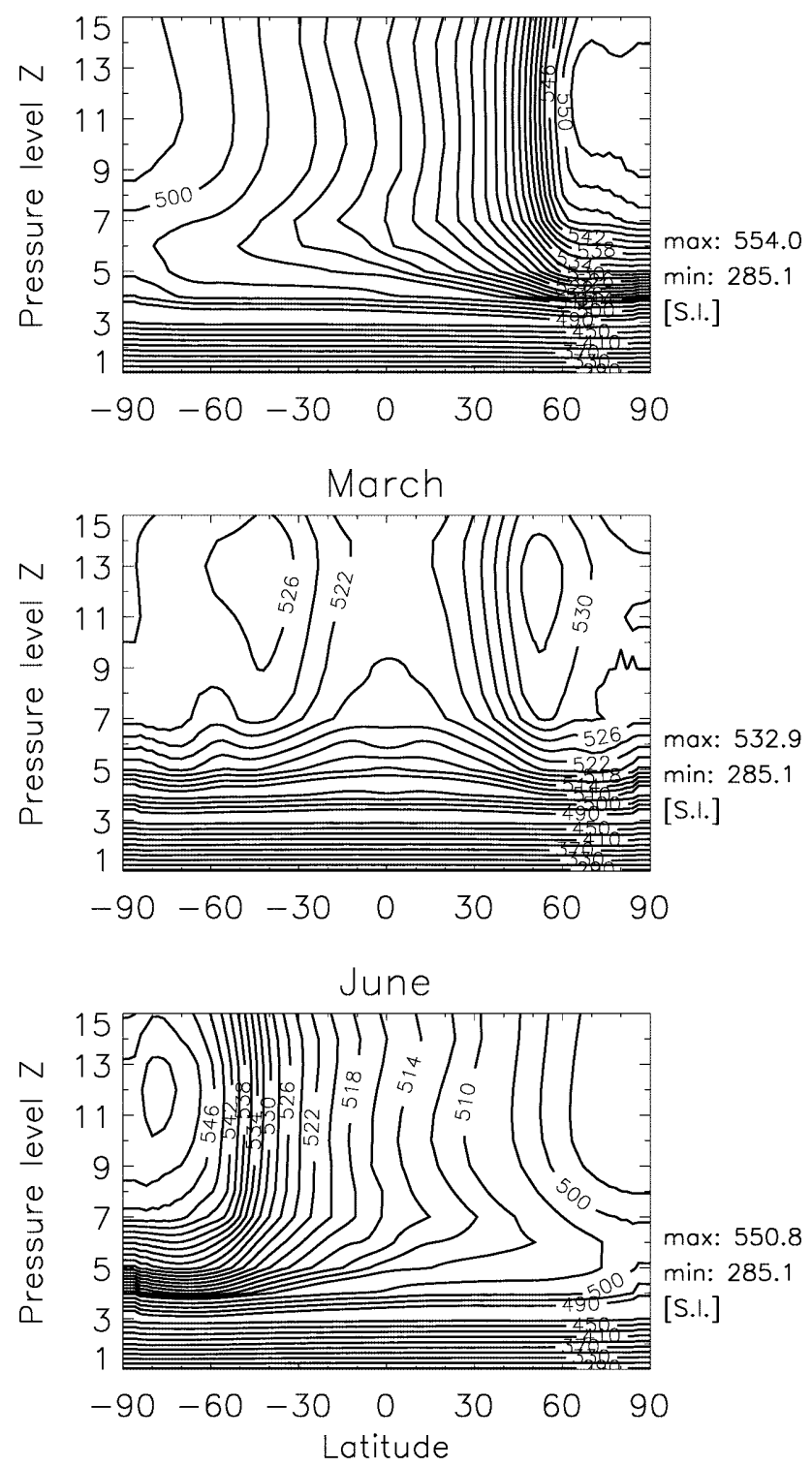

Fig. 5. Zonal averages of the composition $P$-parameter, plotted versus latitude and pressure-level (reduced height $Z$ ), for December, March and June

$\mathrm{N}_{2}$, so that $P$ is not height-independent, as it would be if precise diffusive equilibrium prevailed. In the summer hemisphere, $P$ decreases with height from the top of the photochemically controlled region (around pressurelevel $Z=6$, height $120 \mathrm{~km}$ ) up to pressure-level $Z=10-11$ (roughly 190-230 km, depending on local time and season), and only becomes height-independent above about $Z=11$ (the apparent variations of $P$ at the top, $Z=14-15$, are due to computational effects). The upwelling is balanced by downwelling, which takes place at night and in narrow zones in the daytime winter hemisphere, just equatorward of the auroral oval.

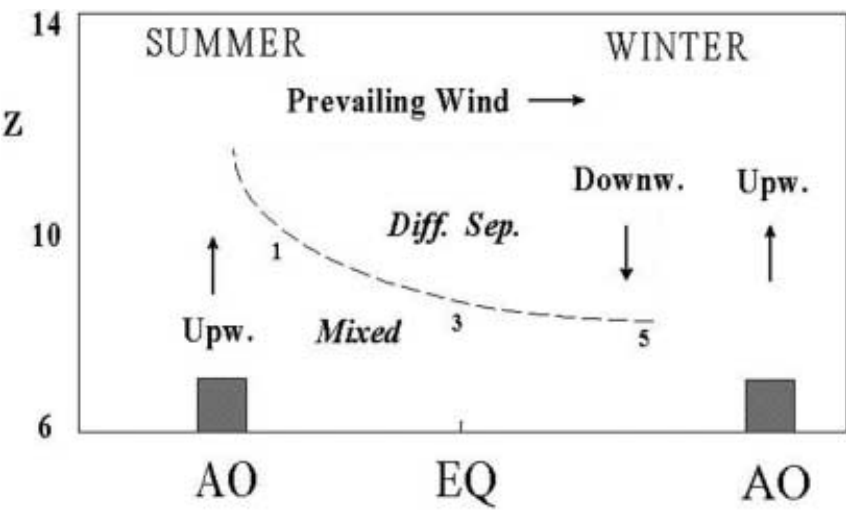

Fig. 6. Sketch of the progressive 'settling', due to molecular diffusion, of thermospheric gases $\left(\mathrm{O}\right.$ and $\left.\mathrm{N}_{2}\right)$ as the circulation carries air from the upwelling zone $(U p w$.$) in the summer hemisphere to the$ downwelling zone (Downw.) in the winter hemisphere, which is just equatorward of the winter auroral oval, where upwelling $(U p w$.) also occurs. During the summer-to-winter motion, the boundary between the region 'Diff.Sep.', where vertical separation is complete, and the 'Mixed' region where diffusive separation is incomplete, gradually moves downwards. The numbers $1,3,5$ represent approximate travel times in days from the region of strongest upwelling, in the vicinity of the summer auroral oval. The vertical scale is labelled (approximately) in pressure-levels $Z$. $\mathrm{AO}=$ auroral oval, $\mathrm{EQ}=$ geographic equator

Above $200 \mathrm{~km}$ the prevailing wind is about $25 \mathrm{~m} \mathrm{~s}^{-1}$ at middle and low latitudes and transports the air about $20^{\circ}$ of latitude per day, so the journey from summer midlatitudes to the winter downwelling zones takes about 5 days. As the air travels, molecular diffusion in the vertical direction gradually restores the distributions of $\mathrm{O}$ and $\mathrm{N}_{2}$ to their normal state with $P$ independent of height. At any particular level, this process takes a time of order $\tau=H^{2} / D\left(\mathrm{O}, \mathrm{N}_{2}\right)$, where $D\left(\mathrm{O}, \mathrm{N}_{2}\right)$ is the appropriate diffusion coefficient for the diffusion of $\mathrm{O}$ and $\mathrm{N}_{2}$ through each other. As this coefficient increases exponentially upwards, $\tau$ decreases exponentially upwards and is short at great heights. We estimate values of $D\left(\mathrm{O}, \mathrm{N}_{2}\right)$ in Sect. 4.5.

Consider a cell of air, initially in the lower thermosphere at high-middle latitudes in summer, which is represented by the left-hand side of Fig. 6. The strong upwelling (Upw) is driven both by solar EUV and auroral heating. The cell rises into the F-layer, carrying its $\mathrm{O} / \mathrm{N}_{2}$ ratio with it and thus locally decreasing the $\mathrm{O} /$ $\mathrm{N}_{2}$ ratio, and then travels towards the winter hemisphere in the direction marked "Prevailing Wind". Different cells travel at different heights, according to where they originate.

Molecular diffusion operates on all the cells in a vertical column, to increase their $\mathrm{O} / \mathrm{N}_{2}$ ratios towards the normal gravitationally controlled condition of "diffusive separation". This process begins at high levels, and progressively works downwards at a rate determined by the time-constant $\tau$, at first rapidly and then more slowly as $\tau$ increases. After $1,3,5 \ldots$ days of the summer-to-winter journey, full diffusive separation is restored down to (but not below) the numbered heights, at which $\tau \sim 1,3,5 \ldots$ days, as indicated by the dashes in Fig. 6 which mark the boundary between the "Diff. 
Sep." and "Mixed" regions. As a result, in the region marked "Diff. Sep." (but outside the zone of strong summer upwelling), $P$ is nearly independent of height (though not of latitude), but its value is higher than in the "Mixed" region.

This process is consistent with the shape of the December and June $P(Z)$ curves in Fig. 5, which gradually straighten out from the top downwards as $P$ increases from summer to winter. This whole process takes long enough for the composition disturbance to travel into the winter hemisphere, which implies that the time scale of restoring diffusive equilibrium, right down to the photochemical region, if of order 5 days. With this time scale, it is clear that $P$ can vary little between day and night. Superimposed on the prevailing motion is the to-and-fro oscillation due to the diurnally-varying winds, but since its amplitude is only about $\pm 1000 \mathrm{~km}$, less than a day's prevailing flow, this oscillation does not change the gross picture just described. As envisaged by Duncan (1969), and demonstrated by the calculations of Rishbeth and MüllerWodarg (1999), the midlatitude circulation terminates at the upwelling zone due to the heating in the winter auroral oval. Just equatorward of the winter auroral oval lies the downwelling zone (marked as 'Downw' in Fig. 6), where there is an enhanced $\mathrm{O} / \mathrm{N}_{2}$ ratio. In "near-pole" longitudes, this zone is at relatively low geographic latitudes and is therefore in sunlight at winter noon, thus giving rise to the "F2-layer winter anomaly" with large noon $N \mathrm{mF} 2$. At "far-from-pole" longitudes, the downwelling zone is at relatively high geographic latitudes and is in darkness at midwinter noon, so $N \mathrm{mF} 2$ is very small.

Fig. 1 shows that, at magnetic latitude $46^{\circ} \mathrm{N}$ (left), the high peaks of $N \mathrm{mF} 2$ in February and October are in regions of high $\mathrm{O} / \mathrm{N}_{2}$ ratio, though at December solstice $N \mathrm{mF} 2$ is depressed by the large solar zenith angle, the geographic latitude here being $54^{\circ} \mathrm{N}$. In contrast, at $56^{\circ} \mathrm{S}$ (right), the largest values of $\mathrm{O} / \mathrm{N}_{2}$ ratio occur in the "farfrom-pole" sector, but $\mathrm{NmF} 2$ has a very deep minimum because of the absence of sunlight, the geographic latitude here being $70^{\circ} \mathrm{S}$.

\subsection{The circulation at equinox}

Now consider the situation at equinox, when the solar EUV input is greatest at low latitudes. It causes strong upwelling by day, accompanied by equator-to-pole thermospheric winds, which is balanced by similarly strong downwelling by night, accompanied by pole-toequator winds. Because of the long time constant for thermospheric composition, there is no net daily disturbance of thermospheric composition at low and middle latitudes, and diffusive equilibrium prevails (though Fig. 5 for March does show some latitude structure, with weak maxima at high midlatitudes). The consequence is that the thermosphere has a greater $\mathrm{O} / \mathrm{N}_{2}$ ratio, both in low latitudes and globally averaged, at equinox as compared to solstice. This semiannual composition change accounts for the semiannual vari- ation of F2-layer electron density at low latitudes. It also accounts for at least some of the semiannual variation in neutral air density (Sect. 4.7) because, as pointed out by Fuller-Rowell (1998), the more atomic composition implies a greater scale height, so the air density decreases upwards more slowly at equinox than at solstice.

The essential difference between equinox and solstice can be expressed in terms of the vertical divergence velocity, $W_{D}$. At equinox, there is no net upwelling in low and middle latitudes, and over $24 \mathrm{~h}$ the timeaveraged upwelling $\int W_{D} \mathrm{~d} t$ is small. At solstice, there is net upwelling in middle and high summer latitudes, with $\int W_{D} \mathrm{~d} t>0$, while $\int W_{D} \mathrm{~d} t<0$ in the downwelling zone at high winter midlatitudes.

The zonal winds (see Fig. 3) carry air from the day side to the downwelling on the night side, thus influencing the variations of $\mathrm{O} / \mathrm{N}_{2}$ ratio. Their role is more important at equinox, when there is no prevailing meridional circulation. At subauroral latitudes, there are strong zonal winds, and the resulting zonal transport of the air is one reason why the $\mathrm{O} / \mathrm{N}_{2}$ ratio does not correspond closely to the vertical divergence. We leave this point for future study.

\subsection{The time constant $\tau$}

We need to estimate the time constant $\tau$ with which a mixture of $\mathrm{O}$ and $\mathrm{N}_{2}$, not initially in gravitational or diffusive equilibrium, tends towards that state (Sect. 4.3). To establish complete diffusive separation, each particle has to diffuse through a vertical distance of order $H$ at the mutual diffusion velocity, which is of order $D\left(\mathrm{O}, \mathrm{N}_{2}\right) /$ $H$. This implies that

$\tau=H^{2} / \mathrm{D}\left(\mathrm{O}, \mathrm{N}_{2}\right)$

From Eq. (26) of Rishbeth et al. (1987), using values from Morgan and Schiff (1964),

$D\left(\mathrm{O}, \mathrm{N}_{2}\right)=(2.6 / p)(T / 273)^{7 / 4}\left[\mathrm{~m}^{2} \mathrm{~s}^{-1}\right]$

where $p, T$ are pressure and temperature. In CTIP, the pressure at any level $Z$ is given numerically by $p(Z)=2.84 \exp (-Z) \mathrm{Pa}$. Representative daytime values for $Z=12$, around the F2 peak, and for $Z=7$, the top of the chemically-controlled region are shown in Table 2 . Since it takes a few time constants $\tau$ to achieve complete diffusive equilibrium, these values are at least

Table 2. Daytime CTIP values at two pressure-levels for equinox at latitude $45^{\circ}$

\begin{tabular}{lcc}
\hline Pressure-level $Z$ & 7 & 12 \\
\hline Pressure $p, \mathrm{mPa}$ & 2.6 & 0.017 \\
Height $h, \mathrm{~km}$ & 127 & 277 \\
Scale height $H, \mathrm{~km}$ & 13 & 41 \\
Temperature $T, \mathrm{~K}$ & 373 & 843 \\
Time constant $\tau$, hours & 22 & 0.4 \\
Diffusion coefficient & 1.7 & 1100 \\
$\quad D\left(\mathrm{O}, \mathrm{N}_{2}\right), 10^{3} \mathrm{~m}^{2} \mathrm{~s}^{-1}$ & & \\
\hline
\end{tabular}


the right order of magnitude for our suggested interpretation.

\subsection{Time scale of seasonal changes}

An interesting question, related to the discussion in Sects. 4.2 and 4.5, is "How long does it take for the thermosphere to respond to the seasonal changes of solar irradiation?" Our modelling cannot provide a detailed answer, because (as explained in Paper I) the Sun's position is changed in steps of one month at a time, not day-by-day. Nevertheless. the model outputs for intermediate months (January-May) show that the solstice-to-solstice changes take place quite quickly, nearly all between 21 February and 21 April, and between 21 August and 21 October. This suggests a "thermospheric time constant" of order 20 days, consistent with the fact that 20 daily runs are needed to settle down the model to a stable state, the neutral gas composition being much slower to settle than the ionization. Another way of estimating the time for the thermospheric composition to adjust to changing condition is as follows. At solstice the prevailing (24-h average) summer-to-winter wind is $25 \mathrm{~m} \mathrm{~s}^{-1}$ or about $2000 \mathrm{~km}$ per day, so it takes a week to traverse the entire circulation cell, which extends over roughly $120^{\circ}$ of latitude or $14000 \mathrm{~km}$. We can expect the time constant for settling down to be two or three times this transit time, which again leads to an estimate of order 20 days.

\subsection{Semiannual variations of the neutral thermosphere?}

Fuller-Rowell (1998) has discussed the semiannual variation of neutral density and scale height. Our modelling accounts for some of it, but not all. Empirical models of the thermosphere generally represent this variation partly as a composition change, which in principle the CTIP modelling explains, and partly as a temperature change, which our modelling does not reproduce. There is experimental evidence from Millstone Hill and St Santin incoherent scatter radars (Alcaydé et al., 1974) that the temperature variation really exists, likewise the semiannual variation of $h \mathrm{mF} 2$ (Papagiannis et al., 1975), even though it is not reproduced by CTIP (Rishbeth et al., 2000).

\subsection{Effects of geomagnetic activity}

Our discussion has so far been confirmed to the quietday thermosphere. In the real thermosphere, the wind pattern is influenced by geomagnetic activity, which enhances the auroral heat sources and increases upwelling at high latitudes, thereby affecting winds and composition. Since geomagnetic activity is greatest at equinox, the equinox patterns of temperature and winds are affected more than the solstice patterns. This additional semiannual effect is not included in the present calculations, but it may roughly be estimated by nothing that:
1. On average, the magnetic $A \mathrm{p}$ index is higher at equinox than at solstice, by about 4 units at solar minimum $\left(F_{10.7}=70\right)$ and 6 units at solar maximum $\left(F_{10.7}=200\right)$;

2. These increases of $A \mathrm{p}$ increase thermospheric temperature, approximately by $15 \mathrm{~K}$ (day) and $25 \mathrm{~K}$ (night) at solar minimum, and by roughly twice these amounts at solar maximum.

These effects on thermospheric temperature and winds are latitude-dependent, so they affect the pattern of winds. According to these figures, the geomagnetic effect seems unlikely to have a major effect on the arguments.

\section{The equatorial zone and electric field effects at low latitudes}

We now return to the question of how electric fields may affect our results. It is well known that electric fields are important in producing the F2-layer "equatorial trough", which appears in the CTIP simulations because of the included model electric fields from Richmond et al. (1980). However, we found that this electric field model does not reliably represent the seasonal variations because, as described in Sect. 3.7 of Paper I, it suppresses the semiannual variation at the magnetic equator. Nevertheless, we expect the model of Richmond et al. (1980) to give reasonably accurate magnitudes of the field. To test the effects in more detail, computational experiments were carried out in which the low-latitude electric field terms were removed, as described in Sect. 2.4 of Paper I.

In the series of runs with no electric field and no convection, the magnetic flux tubes with their "frozenin" plasma are stationary and do not circulate, but the plasma motions due to diffusion and neutral air winds are still constrained by the geomagnetic field. The runs with electric field but no convection represent an artificial situation in which the "Richmond" and "Foster" electric fields are on, so the electric fields transfer momentum to the ions and, through them, to the neutral air, but circulation of the flux tubes is stopped. There are three specific questions about the physics of electric field effects on the F-layer, which can be answered with results from these runs:

First: do low latitude electric fields affect the midlatitude F2-layer? The answer is no: away from the equatorial zone, the midlatitude electron densities in the "no electric field" runs are within $2 \%$ or so of those in the corresponding "standard" runs. Since the electric fields make so little difference at any season (mainly because the distance through which ions and electrons drift during their lifetime is small, only of order $100 \mathrm{~km}$ ), they do not affect the annual and semiannual anomalies at midlatitudes.

Second: the electric field enters the equation of ion motion in two ways: (a) through the resulting collisions between the drifiting ions and the neutral air, which enter the drift and diffusion terms in the equation; and (b) through the " $\mathbf{E} \times \mathbf{B}$ convection" of magnetic flux tubes. Which is more important? On comparing the 
results of the "no electric field, no convection" runs with those of the artificial situation represented by the "with electric field but no convection" runs, the difference is found to be very small. This shows that convective transport has a much greater effect on the plasma distribution than does the motion imparted through the collisional terms of the equation of motion.

Third: do internal polarization fields at middle and low latitudes affect the neutral air composition? The answer is no, for all practical purposes. Detailed examination of the composition versus latitude plots (Rishbeth and Müller-Wodarg, 1999) reveals only small perturbations in low magnetic latitudes, no more than $5 \%$ in $\left[\mathrm{O} / \mathrm{N}_{2}\right]$ ratio. These negative findings are consistent with the idea that dynamo electric fields are insufficiently powerful to produce significant vertical motions of the neutral air (Dougherty, 1961).

\section{Discussion}

\subsection{Electron density and neutral composition}

We now summarize the physical picture that emerges from the modelling, particularly the global morphology of $N \mathrm{mF} 2$. We find that the global distribution of daytime $N \mathrm{mF} 2$ is essentially determined by the Sun, and by the chemical composition of the neutral air upon which the Sun's radiation acts. The important chemical parameter is the atomic/molecular ratio in the F2 layer, conveniently specified by the $\mathrm{O} / \mathrm{N}_{2}$ concentration ratio. We find an east-west asymmetry in $N \mathrm{mF}$, which we attribute to the geometry of the auroral ovals; specifically, that the geographic separation of the northern and southern ovals is greater at western longitudes than at eastern longitudes (Fig. 2).

The global thermospheric circulation is the key to the variations of $\mathrm{O} / \mathrm{N}_{2}$ ratio and hence largely those of $N \mathrm{mF}$ 2. The $\mathrm{O} / \mathrm{N}_{2}$ ratio depends especially on the vertical circulation, and its seasonal changes accompany the change in thermospheric circulation between a basically summer-to-winter pattern around the solstices to a symmetrical pattern at equinox. As for the semiannual variation of neutral density, the results discussed by Fuller-Rowell (1998) are largely supported by the present analysis, except that the CTIP simulations give no significant semiannual variation of thermospheric temperature.

\subsection{Six possible explanations of annual and semiannual variations of $\mathrm{NmF2}$}

As discussed by Rishbeth (1998) and in Sect. 1.2 of Paper I, the suggested causes of seasonal and semiannual variations in the F2-layer include the following:

1. Composition changes due to large-scale dynamical effects in the thermosphere - the mechanism studied by Millward et al. (1996a) and in the present work

2. Variations in geomagnetic activity

3. Solar wind energy (Lal, 1992, 1998)
4. Inputs from below, due to atmospheric waves and tides

5. Changes in atmospheric turbulence and

6. Anisotropy of solar EUV emission in solar latitude (Burkard, 1951).

With no evidence to support it, we dismiss (6). Of the other five, (1) is "internal" to the thermosphere; it depends on motions and chemical changes driven by solar radiation absorbed within the thermosphere (plus the high latitude energy inputs included in the computations, but these are kept constant). The others are driven from outside the thermosphere, either from the magnetosphere and solar wind $(2,3)$, or from below the thermosphere $(4,5)$. As for $(4)$, in Sects. 2.5 and 4.1 of Paper I we gave very limited consideration to the complex question of how waves and tides in the underlying mesosphere may affect the F2-layer, but we conclude later (Sect. 6.3) that they are unlikely to have a major effect on annual and semiannual variations of NmF2. As for mechanism (5), Shimazaki (1972) showed that large-scale convective motions (which are included in our analysis) have much more effect on thermospheric composition than changes in eddy diffusion at the turbopause (which are not), even though the "spoon" terminology might be thought to imply increased turbulent mixing.

Regarding the "geomagnetic" mechanisms $(2,3)$, the first point to make is that our CTIP simulations produce a reasonably good representation of the annual and semiannual variations in $\mathrm{NmF} 2$ with "quiet-day" conditions, without any changes of geomagnetic activity. In reality, geomagnetic activity is rather greater at equinox than at solstices, which actually has the effect of reducing $N \mathrm{mF} 2$ at equinox, and therefore opposes the semiannual variation.

Regarding (3), Lal (1992, 1998) regards the "solar wind" as the cause of all semiannual aeronomic phenomena. To a large extent, this idea is included in mechanism (2) because of the known connection between the solar wind and geomagnetic activity. For example, according to the theory of Russell and McPherron (1973), the semiannual variation of geomagnetic activity depends on the varying geometrical coupling of the interplanetary and terrestrial magnetic fields. Applying this chain of argument to $N \mathrm{mF} 2$ involves the difficult question of how geomagnetic activity affects the F2layer. We need to distinguish between the effects of welldefined "geomagnetic storms" and those of changes in the general level of "background" magnetic activity. The former topic has been discussed by Prölss (1995) and Field et al. (1998) and is not dealt with here. Other mechanisms may need to be considered, for example the possible effect of neutral atoms precipitated from the ring current (Tinsley, 1991).

\subsection{Effect of wave inputs from the mesosphere}

We originally intended to investigate possible ionospheric effects of tidal and wave inputs from the 
mesosphere, mechanism (4). In the end we made no detailed study of these inputs, mainly because the CTIP modelling strongly suggests that most of the annual and semiannual variations originate from mechanism (1), without any coupling with the middle atmosphere. We do not pursue the topic here, partly because of the success of mechanism (1), but also because the subject has been dealt with by Forbes et al. (1993). These authors find that the semidiurnal tidal modes do indeed affect thermospheric composition, and therefore need to be included in any further study of the problem. We might expect the semidiurnal tides to affect the shape of the daily $N(t)$ electron density variations, but these are not discussed in the present studies which concentrate on noon and midnight. Although the tidal inputs do vary with season (see Table 1 of Paper I), we found no real changes in the relative amplitudes of annual and semiannual components of $\mathrm{NmF} 2$ when tides were included (Sect. 4.1 and Fig. 10 of Paper I).

In a review article, Reid (1986) describes a complex seasonal dependence of gravity wave activity in the upper mesosphere and lower thermosphere at midlatitudes, varying with latitude, height range and wave period, and to some extent with the observing technique. There does not emerge any consistent pattern of maximum activity at equinox. Had we introduced gravity wave inputs into our CTIP modelling, we might have found their effects on $N \mathrm{mF} 2$ to be secondary, though the effects on temperature and $h \mathrm{mF} 2$ may not be.

\subsection{The non-importance of electric field effects at midlatitudes}

The discussion of Sect. 5 goes as far as the study of electric field effects can reasonably go with an empirical field model. Nevertheless, we have reached useful conclusions. First, the model electric fields have no important effect on the annual and semiannual variations of $N \mathrm{mF} 2$ at midlatitudes. Second, although the high-latitude electric fields produce joule heating and upwelling, which has worldwide effects on neutral composition, our conclusion that low-latitude electric fields do not affect neutral composition seems safe. Third, our CTIP results shown in Paper I (both with and without the "Richmond" model electric fields) show significant longitude variations in the equatorial zone, which cannot therefore be due to electric fields alone. Further progress requires a fully self-consistent dynamo field model, as developed by Richmond et al. (1992).

\subsection{The annual variation}

The CTIP modelling failed to reproduce the annual (December/June) anomaly in worldwide $N \mathrm{mF} 2$. As explained in Sect. 2.1 of Paper I, the annual 3\% variation of Sun-Earth distance has not been included in our CTIP computations, but the resulting modulation of the incident flux of ionizing radiation seems much too small to account for the anomaly. However, Buonsanto (1986) suggested that there should be an accompanying annual variation of the thermospheric $\mathrm{O} / \mathrm{O}_{2}$ ratio, due to the varying flux of dissociating solar radiation. Study of this suggestion is needed, together with further analysis of ionosonde data concerning the annual anomaly.

\section{Conclusion}

The research described is concerned with the quiet-day F2 layer. It has led to a new overall description of the quiet-day thermospheric circulation, and how it gives rise to both seasonal and semiannual effects in the midlatitude F2-layer. It has given better insight into the complexities of F2-layer behaviour and interactions with the neutral atmosphere. It has essentially confirmed the ideas of Duncan (1969) about the way in which global-scale thermospheric motions produce the composition changes postulated by Rishbeth and Setty (1961). Further work is needed on several detailed topics, including the longitude variations of $N \mathrm{mF} 2$ and $h \mathrm{mF} 2$, the annual variation of $N \mathrm{mF} 2$, and the semiannual variation of $h \mathrm{mF} 2$. Taking account of how the thermospheric circulation is modified by magnetic disturbance, the work can be extended to storm effects in the F2-layer, with possible applications to topical problems of radio propagation predictions and "space weather".

Acknowledgements. This work was supported by the UK Natural Environment Research Council under the Antarctic Special Topic programme AST-4 and used the CRAY-YMP system at the Rutherford Appleton Laboratory. CTIP is a joint collaborative project between the Atmospheric Physics Laboratory, University College London, the School of Mathematics and Statistics, University of Sheffield, and the NOAA Space Environment Center, Boulder, Colorado. We are grateful to the referee for helpful comments.

The Editor in Chief thanks H. Kohl for his help in evaluating this paper.

\section{References}

Alcaydé, D., P. Bauer, and J. Fontinari, Long-term variations of thermospheric temperature and composition, J. Geophys. Res., 79, 629-637, 1974.

Buonsanto, M., Possible effects of the changing Earth-Sun distance on the upper atmosphere, S. Pac. J. Nat. Sci., 8, 58-65, 1986.

Burkard, O., Die halbjährige Periode der F2-Schicht-Ionisation, Archiv Meteorol. Bioklim. Wien, 4, 391-402, 1951.

Dougherty, J. P., On the influence of horizontal motion of the neutral air on the diffusion equation of the F-region, J. Atmos. Terr. Phys., 20, 167-176, 1961.

Duncan, R. A., F-region seasonal and magnetic storm behaviour, J. Atmos. Terr. Phys., 31, 59-70, 1969.

Evans, D. S., T. J. Fuller-Rowell, S. Maeda, and J. C. Foster, Specification of the heat input to the thermosphere from magnetospheric processes using TIROS/NOAA auroral particle observations, Adv. Astronaut. Sci., 65, 1649-1667, 1988.

Field, P. R., H. Rishbeth, R. J. Moffett, D. W. Idenden, T. J. FullerRowell, G. H. Millward, and A. D. Aylward, Modelling composition changes in F-layer storms, J. Atmos. Solar-Terr. Phys., 60, 523-543, 1998. 
Forbes, J. M., R. G. Roble, and C. G. Fesen, Acceleration, heating, and compositional mixing of the thermosphere due to upward propagating tides, J. Geophys. Res., 98, 311-321, 1993.

Foster, J. C., J. M. Holt, R. G. Musgrove, and D. S. Evans, Ionospheric convection associated with discrete levels of particle precipitation, Geophys. Res. Lett., 13, 656-659, 1986.

Fuller-Rowell, T. J., The "thermospheric spoon": a mechanism for the semi-annual density variation, J. Geophys. Res., 103, 39513956, 1998.

Fuller-Rowell, T. J., and D. S. Evans, Height-integrated Pedersen and Hall conductivity patterns inferred from the TIROSNOAA satellite data, J. Geophys. Res., 92, 7606-7618, 1987.

Fuller-Rowell, T. J., D. Rees, S. Quegan, R. J. Moffett, M. V. Codrescu, and G. H. Millward, A coupled thermosphereionosphere model (CTIM), in STEP Handbook of ionospheric models, Ed. R.W. Schunk, Utah State University, Logan, Utah, 217-238, 1996.

Johnson, F. S., Composition changes in the upper atmosphere, in Electron density distributions in the ionosphere and exosphere, Ed. E. Thrane, North-Holland, Amsterdam, 81-84, 1964.

King, G. A. M., The dissociation of oxygen and high level circulation in the atmosphere, J. Atmos. Sci., 21, 231-237, 1964.

Lal, Chaman, Global F2 layer ionization and geomagnetic activity, J. Geophys. Res., 97, 12 153-12 159, 1992.

Lal, Chaman, Solar wind and equinoctial maxima in geophysical phenomena, J. Atmos. Terr. Phys., 60, 1017-1024, 1998.

Millward, G. H., H. Rishbeth, R. J. Moffett, S. Quegan, and T. J. Fuller-Rowell, Ionospheric F2 layer seasonal and semiannual variations, J. Geophys. Res., 101, 5149-5156, 1996 a.

Millward, G. H., R. J. Moffett, S. Quegan, and T. J. Fuller-Rowell, A coupled thermosphere-ionosphere-plasmasphere model (CTIP), in STEP Handbook of ionospheric models, Ed. R. W. Schunk, Utah State University, Logan, Utah, 239-280, 1996b.

Morgan, J. E., and H. I. Schiff, Diffusion coefficients of O and N atoms in inert gases, J. Chem. Phys., 42, 2300, 1964.

Papagiannis, M. D., H. Hassan-Hosseinieh, and M. Mendillo, Changes in the ionospheric profile and the Faraday factor $M$ with Kp, Planet. Space Sci., 23, 107-113, 1975.

Pavlov, A. V., The role of vibrationally excited oxygen and nitrogen in the ionosphere during the undisturbed and geomagnetic storm period of 6-12 April 1990, Ann. Geophysicae, 16, 589601,1998
Prölss, G. W., Ionospheric F-region storms, in Handbook of atmospheric electrodynamics, vol. 2, Ed. H. Volland, CRC Press, Boca Raton, 195-248, 1995.

Reid, I. M., Gravity wave motions in the upper middle atmosphere (60-110 km), J. Atmos. Terr. Phys., 48, 1057-1072, 1986.

Richmond, A. D., M. Blanc, B. A. Emery, R. H. Wand, B. G. Fejer, R. F. Woodman, S. Ganguly, P. Amayenc, R. A. Behnke, C. Calderon, and J. V Evans, An empirical model of quiet-day electric fields at middle and low latitudes, J. Geophys. Res., 85, 4658-4664, 1980.

Richmond, A. D., E. C. Ridley, and R. G. Roble, A thermosphere ionosphere general circulation model with coupled electrodynamics, Geophys. Res. Lett., 19, 601-604, 1992.

Rishbeth, H., On the F-layer continuity equation, J. Atmos. Terr. Phys., 48, 511-519, 1986.

Rishbeth, H., How the thermospheric circulation affects the ionospheric F2-layer, J. Atmos. Terr. Phys., 60, 1385-1402, 1998.

Rishbeth, H., and O. K. Garriott, Introduction to ionospheric physics, Academic Press, New York, 1969.

Rishbeth, H., and I. C. F. Müller-Wodarg, Vertical circulation and thermospheric composition: a modelling study, Ann. Geophysicae, 17, 794-805, 1999.

Rishbeth, H., and C. S. G. K. Setty, The F-layer at sunrise, J. Atmos. Terr. Phys., 21, 263-276, 1961.

Rishbeth, H., T. J. Fuller-Rowell, and D. Rees, Diffusive equilibrium and vertical motion in the thermosphere during a severe magnetic storm: a computational study, Planet. Space Sci., 35, 1157-1165, 1987.

Rishbeth, H., K. J. F. Sedgemore-Schulthess, and T. Ulich, Semiannual and annual variations in the height of the ionospheric F2-peak, Ann. Geophysicae, 18, 285-299, 2000.

Russell, C. T., and R. L. McPherron, Semiannual variation of geomagnetic activity, J. Geophys. Res., 78, 92-107, 1973.

Shimazaki, T., Effects of vertical mass motions on the composition structure in the thermosphere, Space Research, 12, 1039-1045, 1972.

Tinsley, B. A., Neutral atom precipitation - a review, J. Atmos. Terr. Phys., 43, 617-632, 1981.

Zou, L., H. Rishbeth, I. C. F. Müller-Wodarg, A. D. Aylward, G. H. Millward, T. J. Fuller-Rowell, D. W. Idenden, and R. J. Moffett, Annual and semiannual variations in the ionospheric F2-layer: I. Modelling, Ann. Geophysicae, companion paper, 2000. 